\title{
Assessment of the Effect of Catosal on the Stimulation of Ovogenesis in Sterlet During Pre-spawning Period
}

\author{
Natalia Matvienko ${ }^{1, *}(\mathbb{D})$, Alexander Koziy ${ }^{2}$ (D) Alexander Didenko ${ }^{1}\left(\mathbb{D}\right.$, Issak Sherman ${ }^{2}$ \\ ${ }^{1}$ Institute of Fisheries NAAS, Obukhivska 135, Kyiv, 03164, Ukraine. \\ ${ }^{2}$ Kherson State Agrarian University, Stritens'ka St. 23, Kherson, 73006 Ukraine.
}

\section{How to cite}

Matvienko, N., Koziy, A., Didenko, A., Sherman, I. (2022). Assessment of the Effect of Catosal on the Stimulation of Ovogenesis in Sterlet During PreSpawning Period. Aquaculture Studies, 22(1), AQUAST583. http://doi.org/10.4194/AQUAST583

\section{Article History \\ Received 26 January 2021 \\ Accepted 28 September 2021 \\ First Online 13 October 2021 \\ Corresponding Author \\ Tel.: +380636283417 \\ E-mail: mnarine73@ukr.net}

\section{Keywords}

Starlet

Pre-spawning feed

Catosal

Butaphosphamide

Oocyte

Eggs

Physiological status

\begin{abstract}
Optimization of the process of sterlet feeding in recirculating aquaculture systems allows improving the physiological status and pre-spawning performance of fish. The addition of the organophosphorus compound Catosal based on butaphosphamide to pre-spawning feeds leads to an increase in glycogenogenesis in hepatocytes, which manifests itself as a decrease in cell and nucleus area (by 1.20 and 1.31 times), stabilization of nucleoplasmic ratios (0.28-0.25). Butaphosphamide also causes an increase in hemoglobin and serum protein concentrations by $6.1 \mathrm{~g} / \mathrm{L}$ and $3.92 \mathrm{~g} / \mathrm{L}$, respectively. An increase in the live weight of sterlet by $98.0 \mathrm{~g}$ and an absolute increase in weight by $1.96 \mathrm{~g}$ associated with an improvement in hematological parameters was observed. The excess phosphorus in the form of butaphospham, which is not involved in the process of glycogenesis, is transported to gonads and stimulates vitellogenesis. The acceleration of oocyte development is determined upon reaching the optimal polarization coefficient $(0.05 \leq \mathrm{Pc} \leq 0.10$, category II).
\end{abstract}

\section{Introduction}

The culture of sturgeons for caviar is based on feeding adapted brood fish with a variety of artificial feeds, which most often include dry granulated feeds or their mixtures with small amounts of premixes (Buirov et al., 2016; Koziy, Sherman, 2018). As practical experience shows, among a variety of feeds used in aquaculture in Ukraine, artificial feeds manufactured by "Aller Aqua" (Poland) are most in demand. In particular, components of "Aller Metabolica" feed, which include fish meal, fish oil, pea protein, soy protein, hemoglobin meal, rapeseed, yeast, vitamins, and mineral supplements, can satisfy the nutritional needs of all sturgeon species.

Addition of premixes to fish feeds before spawning can promote an increase in fish body weight. The specialized feed "Aller Sturgeon REP" (Poland) allows obtaining eggs of all sturgeon species (Khmelnitsky, 2010). However, such a feed mixture is not effective enough for the stimulation of egg maturation, since individual species-specific changes occurring in fish body were not taken into account during the development of this feed formula. Thus, modification of feeds for sterlet should be focused on enriching their composition with additional components that are as close as possible to the physiological needs of fish.

A variety of stimulants are used in animal husbandry to maintain metabolism in cattle and poultry, among which is butaphosphamide, an organic phosphorus compound with no analogues, which surpasses conventional stimulants in physiological action (Koziy, 2002). Phosphorus compounds affect many assimilation processes occurring in the body and 
play a leading role in the activity of the central nervous system and in processes occurring in the membranes of intracellular systems and muscles, including the heart (Ivanov, 2000). The metabolism of phosphorus compounds is closely related to the metabolism of fats and proteins (Smith, 1986). The role of organic phosphorus compounds in energy supply of vital processes in fish is also significant (Amineva, 1984).

With many positive effects on systems and organs, organic phosphorus compounds are not accumulated in fish tissues and do not have adverse effects typical for stimulants and inorganic phosphorus (Shakirov, 2009; Medvedev et al, 2014).

Butaphosphamide included in Catosal is an organophosphorus compound that stimulates protein synthesis, improves glucose metabolism in blood, normalizes liver function, and increases the body's nonspecific resistance. It is also important that butaphosphamide normalizes hydrocortisone levels in stress conditions (Radionov, 2019). Catosal is used to increase productivity in animals and treat infertility (Plemyashov, 2010). However, information on detailed histological monitoring and pathways of stimulation of vitellogenesis by butaphosphamide in fish is absent. Some studies showed a positive effect of this product on mesoderm histogenesis in poultry embryos (Koziy, 2003). However, there is no information on the use of Catosal in fish farming. In this regard, it is important to study the effect of this product on the course of vitellogenesis in fish, since the pre-spawning period is a critical period of fish embryo development.

Thus, the aim of the work was to study the effect of the organophosphorus compound Catosal based on butaphosphamide in the composition of a pre-spawning feed on certain biological parameters of sterlet. Particular attention was focused on studying the response of tissues of the digestive system and finding ways to stimulate oocyte development.

\section{Materials and Methods}

\section{Fish Keeping and Feeding}

The experiment was conducted at the recirculating aquaculture system (RAS) farm «Oasis Bisan» LLC (Mykolaiv, Ukraine). The experiment lasted 50 days from 20.09.2019 to 08.11.2019. Overall, 200 age-2+ sterlet females with an average body weight of $2071 \pm 62.2 \mathrm{~g}$ were used in the experiment. Experimental fish were divided into two groups (control and experimental), each group containing 100 fish. A day before the experiment, fish were tagged with individual PIT-tags (Animal ID, Sweden) with a diameter of $1.8 \mathrm{~mm}$, which were implanted into the dorsal part under the $5^{\text {th }}$ scute. Each group of fish was kept under RAS conditions in 20 $\mathrm{m}^{3}$ plastic tanks with a stocking density of $10.3 \mathrm{~kg} / \mathrm{m}^{3}$. Water temperature at the beginning of the experiment was $5-6^{\circ} \mathrm{C}$, which was gradually raised during the experiment period to the pre-spawn optimum of $17^{\circ} \mathrm{C}$.
Fish of the control group were fed with a compound feed taking into account the peculiarities of feeding and species physiology. The feed was specially developed and produced at the "Oasis Bisan» LLC within the framework of this study and included: minced fresh Black Sea sprat $(300.0 \mathrm{~g} / \mathrm{kg})$ caught in the Kakhovka reservoir, dried zooplankton $(300.0 \mathrm{~g} / \mathrm{kg})$, fish meal $(95.0 \mathrm{~g} / \mathrm{kg})$, sprouted wheat grains $(200.0 \mathrm{~g} / \mathrm{kg})$, and wheat flour $(95.0 \mathrm{~g} / \mathrm{kg})$ as a binding agent. This feed was supplemented with the premix "PO-4" (Russia), which contained vitamins A, D1, E, C, B1, B2, B5, B6, B12, BC, $\mathrm{B} 4, \mathrm{H}, \mathrm{K}$, antioxidant, and excipient. The use of the premix is justified by the need to maintain the optimal vitamin and mineral balance and stabilize the digestive tract of fish. All feed components were combined in a soft pasty fraction.

Fish of the experimental group were fed with an experimental mixture of the same composition supplemented with a metabolism stimulant Catosal (Bayer, Germany) as a liquid admixture containing (per $100.0 \mathrm{ml}$ ): $10.0 \mathrm{~g}$ of butaphosphamide, $0.005 \mathrm{~g}$ of cyanocobalamin, and $0.1 \mathrm{~g}$ of methyl-4hydroxibenzoate.

The standard dosage of Catosal for animals is 1.0 $\mathrm{ml} / \mathrm{kg}$ of feed. Catosal dosage for the experiment was determined empirically and was $2.0 \mathrm{ml} / \mathrm{kg}$ of feed taking into account its absolute safety and losses due to partial leaching from the feed.

Fish during the experiment were fed four times a day at 8:00, 12:00, 16:00, and 20:00. Approximately 215 $\mathrm{g}$ of the feed were distributed manually in each tank at each feeding event.

\section{Chemical Test}

Amino acid composition of pre-spawning feeds was determined at the accredited chemical laboratory of the Fisheries-Ecological Faculty of the Kherson State Agrarian University according to "Normative methods of the veterinary-sanitary expertise of food products (Kurtiak et al. 2000; Seregin et al., 2018). Feed samples were preliminary prepared using acidic hydrolysis in $5 \mathrm{M}$ $\mathrm{HCl}$ solution $\left(110^{\circ} \mathrm{C}, 24 \mathrm{~h}\right)$ with the addition of norleucine as a reference. For the detection of methionine and cysteine, the preliminary prepared samples were oxidized by $50 \%$ performic acid. Further analysis was conducted by HPLC (Shimadzu LC-20 Prominence, Belgium). The samples used were diluted in ready-to-use buffer solutions (Sevko \& Co, Russia). Calculations of amino acid concentrations were performed according to the reference sample (Sykam S 500 System, Germany).

\section{Growth Performance and Survival Rate}

To reduce stress in fish, their body weights and survival rates were registered at the beginning and at the end of the experimental period. Twenty randomly taken fish with individual PIT-tags from each group were 
weighed on an electronic balance with an accuracy of $10.0 \mathrm{~g}$ before and after the experiment.

Specific growth rate in weight was calculated according to following formula:

$$
S G R=W_{1}-W_{0} / t
$$

Where:

$S G R$ : specific growth rate $(\mathrm{g}) ; W_{0}$ : initial fish weight (g); W1: fish weight at the end of the study period (g); $t$ : time (d).

The survival rate was calculated as the percentage of fish survived by the end of the experiment.

\section{Hematological Tests}

Major physiological and biochemical parameters of blood were used to assess the functional state of sterlet females. In each group, ten fish were taken for this analysis, which was performed at the end of the experiment without taking into account the dynamics of hematological changes. Blood was drawn from the caudal artery according to Kalaida et al. (2013). The total volume of blood collected from each fish $(2.0 \mathrm{ml})$ was divided by the quantity needed for hematological studies (erythrocyte count in the Goryaev's chamber, measurement of hemoglobin by Sahli's method).

The digestive tract fullness of fish during the period of adaptation to pre-spawning feeds was determined according to the 6-point Lebedev's scale (Kalaida et al., 2013). For this, three fish from each group were slaughtered periodically (day 1, 25, and 50) and their intestines were opened. The digestive tract fullness was expressed in parts per ten thousand (\%oo).

\section{Histological Studies}

Histological studies were performed using ten fish from each group at the end of the experiment. Fish were slaughtered and their stomach, liver and gonads (organs, which react to changes in feeds more pronouncedly) were removed. Tissue samples were processed using methods specially developed for histological diagnostics of tissues of aquatic organisms (Kalaida et al., 2013). Histological samples were processed as follows: fixation of samples in Bouin's fluid for $48 \mathrm{~h}$ at $20-30^{\circ} \mathrm{C}$; dehydration with $100 \%$ diethylene dioxide for $30 \mathrm{~min}$ at $30^{\circ} \mathrm{C}$; intermediator - O-xylene for $20 \mathrm{~min}$ at $30^{\circ} \mathrm{C}$; incubation in a plastic mixture: paraffin $(85-90 \%)+$ lanolin (10-15\%) for $25 \mathrm{~min}$ at $60^{\circ} \mathrm{C}$, two replacements. Histological sections were made using a sledge microtome and stained with an aqueous solution of hematoxylin (Böhmer's formula) and modified Hart's fuchselin. Trophic inclusions of oocytes were stained with picro-fuchsin and Heidenhain's iron hematoxylin. Histological preparations were mounted on slides in Canadian balsam.

Microphotographs were done using an E. Leitz "Diaplan" Wetzlar microscope with a Linvatec-2 halogen light source (Linvatec, USA) of 10-240 kWn and a digital camera Nikon D-60 (Austria) with the use of a standard $1.6^{\mathrm{x}}$ trinocular mounting and a digital built-in digital exposure detector "Minolta-EK" (Japan). Contrast enhancement of histological preparations was performed using a "FGPM 2,5" corrective filter (Belarus).

Oocyte polarization index (PI) was calculated according to following formula (Chebanov \& Galich, 2013):

$$
P I=I / L, \text { where: }
$$

Pl: oocyte polarization coefficient; I: distance from the germinal vesicle (outer edge) to the animal pole; $L$ : distance from the animal pole to the vegetal pole.

Morphometric measurements of tissue structures were performed using a built-in ocular micrometer.

Acquisition of reliable information in determining the direction and specificity of tissue rearrangements was achieved using the method of plastic reconstruction. This method includes making thin (3.0 $\mu \mathrm{m})$, spatially oriented histological sections with the subsequent creation of a 3D image (MICAM, Belgium).

Corrective processing of microphotographs was carried out using Microsoft Office Picture Manager and F S Viewer (Kalaida et al., 2013).

\section{Radioautographic Studies}

Radioautographic studies were conducted for a qualitative assessment of the radioactivity of trophic inclusions of sterlet eggs. Dose selection and further dilution of a radioactive substance was performed according to Ozeretskovskaya (1964) method adapted for aquarium experiments (Koziy, 2007). The modified method consists in adding radioactive monosodium phosphate $\left(\mathrm{NaH}_{2} \mathrm{P}^{32} \mathrm{O}_{4}\right)$ to the feed mixture given to fish as a single dose. The optimal activity of the isotope added to the feed was $0.263 \mu \mathrm{Ci} / \mathrm{L}$ that corresponded to $3.47 \mathrm{mg} P / \mathrm{L}$, which was achieved by stabilizing its dose with a non-radioactive analogue $\left(\mathrm{NaH}_{2} \mathrm{P}^{31} \mathrm{O}_{4} 4\right)$ and was determined by the absence of a radiation effect in fish. The exposure of $\mathrm{NaH}_{2} \mathrm{P}^{32} \mathrm{O}_{4}$ was 14 days, which corresponded to the achievement of the isotope halflife in the final phase of the experiment. Registration of $\mathrm{P}^{32}$ in oocytes was carried out using an automatic liquid scintillation counter Hidex $300 \mathrm{SL}$ (Finland). Radioautographs were obtained by developing a blackand-white colloidal photographic emulsion of Rockland (Spain) applied to histological specimens.

\section{Data Analysis}

Data were expressed as a mean \pm standard deviation. Student's $t$-test was used to compare means of paired samples. The differences were considered significant if $\mathrm{P}<0.01$. Data were processed in Statistica, Version 20. 


\section{Results and Discussion}

\section{Biological Indicators}

At the beginning and at the end of the experiment, the quality of sterlet females was assessed using individual biological parameters (Table 1). The average feed intake in the experimental group exceeded that in the control group by $20 \%$ with the same daily rate and total amount of the feed used (Table 1). The final weight of the fish, which consumed the optimized prespawning feed, significantly exceeded that of the control group ( $t$-test, $\mathrm{P}<0.01$ ).

According to Table 2, the physiological and biochemical parameters in all groups corresponded to the biological normal values for age-2+ fish (Aldokhin et al., 2018).

Fish of the experimental group had significantly higher hemoglobin and serum protein concentrations compared to control: $6.1 \mathrm{~g} / \mathrm{L}$ and $3.9 \mathrm{~g} / \mathrm{L}$, respectively.

The dynamics of the digestive tract fullness index showed that the intensity of food consumption by the fish of the experimental group during the preparation for spawning increased (Figure 1).

As Figure 1 shows, fish of both control and experimental groups did not consume feed readily at the initial stages of feeding resulting in low values of the digestive tract fullness. In the control group, feed consumption increased almost 2-fold and 3-fold, respectively, on days 25 and 50 of the experiment. On the contrary, in the experimental group, these values varied more significantly. This fact was confirmed by results of the histological analysis of the stomach and liver (Figure 2).

\section{Morphological Observations}

\section{Reaction of the Digestive System}

Figure 2 shows differences in the functioning of the gastric mucosa. Fish of the control group had lumens of the majority of ducts to be somewhat narrowed indicating low secretory activity of the gastric glands (Figure 2A). On the contrary, fish fed with a feed supplemented with Catosal (Figure 2B) had an increased activity of their mucosa, which at the micro level was detected in the form of a sufficient amount of secretion in the duct lumens (observed as an optical void).

In a comparative aspect, cytological differences in fish hepatocytes are seen in the cytoplasm structure and staining intensity of the nucleus. Sterlet hepatocytes in the control group (Figure 2C) are characterized by distinct cytoplasmic vacuolization demonstrating moderate lipostasis. Cell nuclei are somewhat hyperchromatic compared to the main stain. The optical voids of vacuoles in fish hepatocytes in the experimental group are practically absent (Figure 2D). The acquisition of a narrow specialization by the cells is visually confirmed by the acquisition of specific granularity by the cytoplasm. The cell nuclei are light, vesicular, with a clearly distinguishable nucleola and clumps of chromatin.

It was also found that hepatocytes differed by the analogous cytological features depending on the effect of the composition of the pre-spawning feed (Table 3 ).

Analysis of the obtained data (Table 3) allows concluding that a 1.2-fold decrease in the cell area leads to a 1.3-fold decrease in the nucleus area, respectively. A stabilization of the nucleoplasmic ratio $(0.28-0.25)$ was also observed.

\section{Development of Oocytes}

Females, which underwent ultrasound scanning and selection based on the principle of slightly varying length-weight characteristics, were tested stepwise to determine the degree of maturity of their eggs. The study allowed drawing up a picture of the development of fish eggs (Figure 3, 4).

On day 1 of the experiment, stage II oocytes were in the period of previtellogenic growth (Figure $3 \mathrm{~A}$ ). Some oocytes were in the state of the beginning of

Table 1. Some productive parameters of sterlet when using different types of pre-spawning feeds

\begin{tabular}{|c|c|c|c|}
\hline \multirow{2}{*}{ Parameters } & \multicolumn{2}{|c|}{ Group } & \multirow[t]{2}{*}{ P-value } \\
\hline & Control & Experimental & \\
\hline Feed & Experimental feed & $\begin{array}{c}\text { Experimental feed } \\
+5 \% \\
\text { Catosal, } 2.0 \mathrm{ml} / \mathrm{kg}\end{array}$ & - \\
\hline Daily rate of compound feed, $g$ & 860 & 860 & - \\
\hline Daily rate of compound feed, $g$ & 20 & 20 & - \\
\hline \multicolumn{4}{|l|}{$\%$ of biomass } \\
\hline Total feed used, kg & 43.00 & 43.00 & - \\
\hline Average feed intake, $\%$ & $75.0 \pm 2.0$ & $95.0 \pm 3.0$ & $P<0.01$ \\
\hline \multicolumn{4}{|l|}{ Weight, g } \\
\hline initial & $2065 \pm 57.6$ & $2205 \pm 70.1$ & $P<0.05$ \\
\hline final & $2077 \pm 66.8$ & $2315 \pm 77.4$ & $P<0.01$ \\
\hline Absolute weight gain, $\mathrm{g}$ & $2.8 \pm 0.14$ & $4.8 \pm 0.16$ & $P<0.01$ \\
\hline SGR $\left(\%\right.$ day $\left.^{-1}\right)$ & 2,00 & 1,91 & $\mathrm{P}<0.05$ \\
\hline Survival rate, $\%$ & 100 & 100 & - \\
\hline
\end{tabular}


Table 2. Some hematological parameters of sterlet fed with different feeds during pre-spawning period

\begin{tabular}{lcccc}
\hline Group & Serum protein concentration & Total lipids in blood serum & Hemoglobin & Erythrocyte count \\
& $\mathrm{g} / \mathrm{L}$ & $\mathrm{g} / \mathrm{L}$ & $\mathrm{g} / \mathrm{L}$ & $10^{6} / \mathrm{mm}^{3}$ \\
\hline Control & $21.24 \pm 4.52$ & $2.67 \pm 0.7$ & $65.1 \pm 17.22$ & $0.773 \pm 0.09$ \\
Experimental & $25.16 \pm 7.21$ & $3.08 \pm 0.6$ & $71.2 \pm 19.18$ & $1.0 \pm 0.05$ \\
Confidence & $\mathrm{P}<0.01$ & $\mathrm{P}<0.05$ & $\mathrm{P}<0.01$ & $\mathrm{P}<0.05$ \\
\hline
\end{tabular}

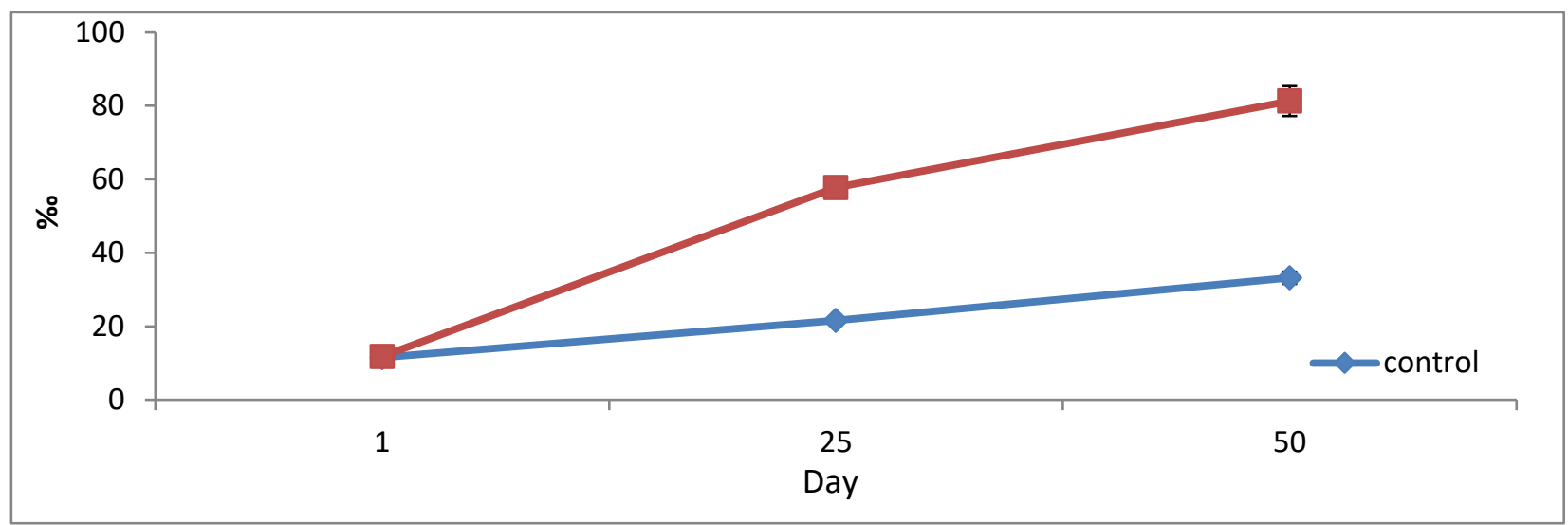

Figure 1. Gastrointestinal tract fullness index during the period of adaptation to the pre-spawning feed

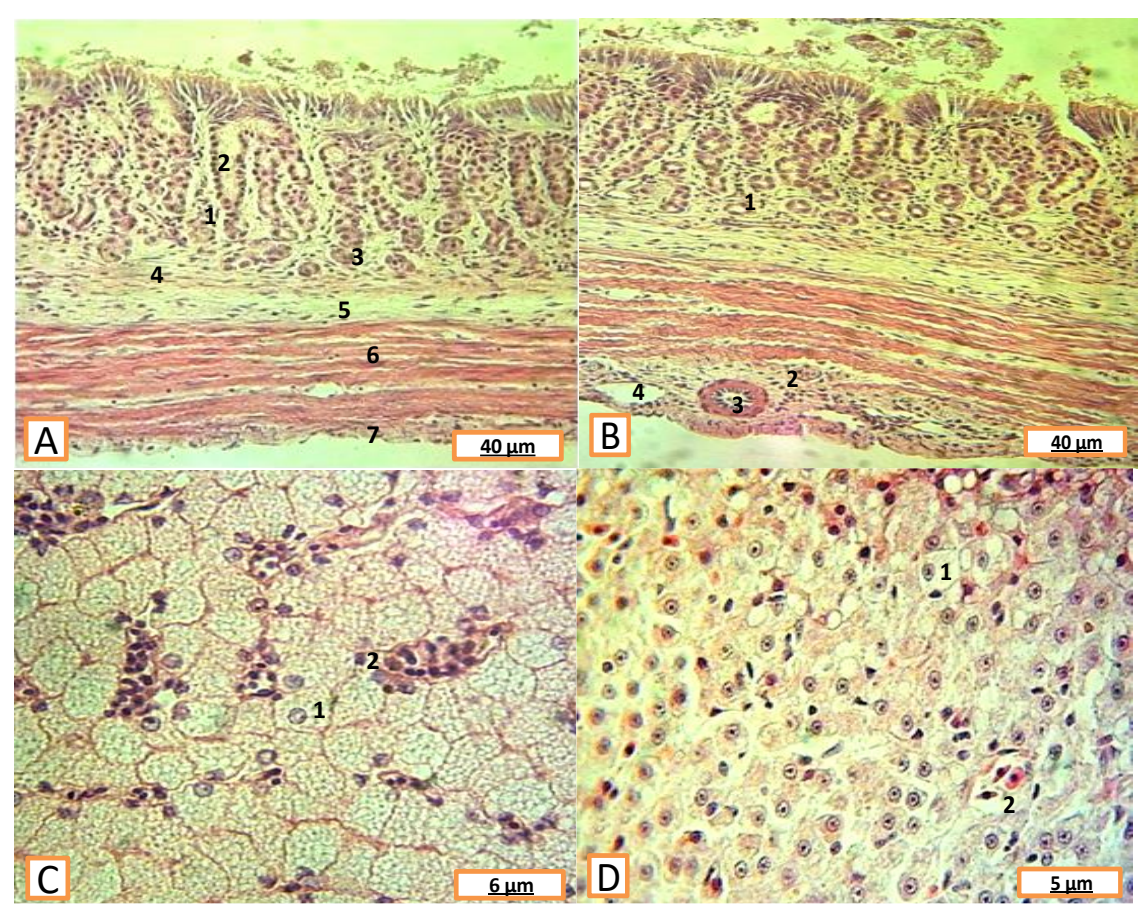

Figure 2. Reaction of gastric mucosa (A, B) and hepatic parenchyma (C, D) of sterlet to the composition of the pre-spawn feed.

vitellogenesis (Figure 3B). The oocyte diameter (in the phase of a single-layer follicle) ranged within 65-224 $\mu \mathrm{m}$.

On day 25 of the experiment, the histological picture of sterlet oocytes in the control group corresponded to the maturity stage II-III (Figure 3C). Three yolk fractions were seen in the ooplasm: peripheral, middle and perinuclear. Oocyte diameter varied from 731 to $1025 \mu \mathrm{m}$. The histological picture of fish oocytes in the experimental group corresponded to the maturity stage III. Vitellogenic oocytes in the pigmentation phase prevailed among the generations present in the ovary (Figure 3E). Oocyte diameter varied from 1137 to $1824 \mu \mathrm{m}$.

The histological picture of oocytes in the control group in the final phase of the experiment corresponded to the maturity stage IV (incomplete) (Figure 3F). Relatively large oocytes with diameters of 1546-2368 $\mu \mathrm{m}$ were observed in the ovary. In this period, the prevalence of mature oocytes (1794-2787 $\mu \mathrm{m})$ were registered in fish of the experimental group that was typical for the maturity stage IV (completed) (Figure 3G, H). 
Table 3. Cytological characteristics of the marginal zone of sterlet liver parenchyma with different compositions of the pre-spawning feed

\begin{tabular}{lcccccc}
\hline \multirow{2}{*}{ Group } & \multicolumn{2}{c}{ Hepatocyte length, $\mu \mathrm{m}$} & \multicolumn{3}{c}{ Area, $\mathrm{S}, \mu \mathrm{m}^{2}$} & \multirow{2}{*}{ NC ratio } \\
\cline { 2 - 5 } & $\mathrm{AxB}_{\text {cells }}$ & $\mathrm{AxB}_{\text {nuclei }}$ & cells & nuclei & cytoplasm & \\
\hline Control & $8.1 \times 5.6 \pm 1.12$ & $3.5 \times 2.8 \pm 0.024$ & $44.25 \pm 7.43$ & $9.80 \pm 0.35$ & $34.75 \pm 4.86$ & $0.28 \pm 0.04$ \\
Experimental & $7.4 \times 5.0 \pm 0.95$ & $3.4 \times 2.2 \pm 0.027$ & $36.98 \pm 5.92$ & $7.48 \pm 0.29$ & $29.50 \pm 6.84$ & $0.25 \pm 0.03$ \\
Confidence Level & $\mathrm{P}<0.05$ & - & $\mathrm{P}<0.01$ & $\mathrm{P}<0.05$ & $\mathrm{P}<0.01$ & $\mathrm{P}<0.01$ \\
\hline
\end{tabular}

Table 4. Cytomorphological parameters of sterlet oocytes

\begin{tabular}{|c|c|c|c|}
\hline \multirow{2}{*}{ Group, Maturity stage* } & \multicolumn{3}{|c|}{ Cytomorphological parameters of sterlet oocytes } \\
\hline & Oocyte diameter, $\mu \mathrm{m}$ & Nucleus diameter, $\mu \mathrm{m}$ & NC ratio \\
\hline \multicolumn{4}{|c|}{ Day 1} \\
\hline Control/Experimental II & $\begin{array}{l}144.5 \pm 31.2 \\
65.0-224.0\end{array}$ & $\begin{array}{l}52.75 \pm 8.6 \\
47.0-58.5\end{array}$ & 0.37 \\
\hline Confidence Level & - & - & - \\
\hline \multicolumn{4}{|c|}{ Day 25} \\
\hline $\begin{array}{l}\text { Control, } \\
\text { II-III }\end{array}$ & $\begin{array}{l}1202.8 \pm 42.3 \\
731.3-1674.3\end{array}$ & $\begin{array}{l}300.7 \pm 19.4 \\
295.8-305.6\end{array}$ & 0.25 \\
\hline $\begin{array}{l}\text { Experimental, } \\
\text { III }\end{array}$ & $\begin{array}{c}1280.5 \pm 188.7 \\
1137.2-1423.7\end{array}$ & $\begin{array}{l}281.7 \pm 15.7 \\
275.0-288.4\end{array}$ & 0.22 \\
\hline Confidence level & $P<0.05$ & $P<0.05$ & $P<0.05$ \\
\hline \multicolumn{4}{|c|}{ Day 50} \\
\hline $\begin{array}{l}\text { Control, } \\
\text { IV (completed) }\end{array}$ & $\begin{array}{c}1957.0 \pm 173.9 \\
1546.0-2368.0\end{array}$ & $\begin{array}{l}371.8 \pm 62.3 \\
368.3-375.3\end{array}$ & 0.19 \\
\hline $\begin{array}{l}\text { Experimental, } \\
\text { IV (uncompleted) }\end{array}$ & $\begin{array}{c}2290.5 \pm 186.5 \\
1794.0-2787.0\end{array}$ & $\begin{array}{r}332.5 \pm 24.8 \\
330.7-334.3\end{array}$ & 0.14 \\
\hline Confidence level & $\mathrm{P}<0.05$ & $P<0.05$ & $\mathrm{P}<0.01$ \\
\hline
\end{tabular}

Table 5. Oocyte polarization coefficient of sterlet at different compositions of the pre-spawning feed

\begin{tabular}{|c|c|c|c|c|c|c|}
\hline \multirow{2}{*}{ Group } & \multirow{2}{*}{ Female№ } & \multirow{2}{*}{$\mathrm{l}_{1},{ }^{*} \mathrm{~cm}$} & \multirow{2}{*}{ Weight,kg } & \multicolumn{2}{|c|}{ Oocyte size, $\mathrm{mm}$} & \multirow{2}{*}{$\begin{array}{c}\text { Oocyte polarization } \\
\text { coefficient, \% }\end{array}$} \\
\hline & & & & Vertical & Horizontal & \\
\hline \multirow{4}{*}{ Control } & 1 & 61.0 & 2.09 & $2.42 \pm 0,12$ & $2.23 \pm 0,13$ & $9.65 \pm 1,14$ \\
\hline & 2 & 62.0 & 2.1 & $2.41 \pm 0,17$ & $2.19 \pm 0,17$ & $14.21 \pm 1,31$ \\
\hline & 3 & 63.0 & 2.1 & $2.44 \pm 0,13$ & $2.18 \pm 0,17$ & $13.42 \pm 1,18$ \\
\hline & 4 & 64.0 & 2.2 & $2.46 \pm 0,19$ & $2.26 \pm 0,13$ & $9.41 \pm 1,17$ \\
\hline Mean, $\bar{X}$ & - & 62.5 & 2,12 & $2,43 \pm 0,15$ & $2,21 \pm 0,15$ & $11,67 \pm 1,20$ \\
\hline \multirow{4}{*}{ Experimental } & 1 & 65 & 2.4 & $2.43 \pm 0,11$ & $2.21 \pm 0,19$ & $8.08 \pm 1.08$ \\
\hline & 2 & 66 & 2.5 & $2.45 \pm 0,16$ & $2.24 \pm 0,14$ & $6.82 \pm 0.85$ \\
\hline & 3 & 66 & 2.4 & $2.46 \pm 0,18$ & $2.20 \pm 0,16$ & $7.03 \pm 0.69$ \\
\hline & 4 & 65 & 2.5 & $2.44 \pm 0,12$ & $2.27 \pm 0,12$ & $7.14 \pm 0.74$ \\
\hline Mean, $\bar{x}$ & - & 65.5 & 2,45 & $2.45 \pm 0.14$ & $2.23 \pm 0.15$ & $7.27 \pm 0.77$ \\
\hline Confidence Level & - & - & - & - & - & $P<0.05$ \\
\hline
\end{tabular}

Note. Body length to the end of middle rays of the caudal fin.

Table 6. Oocyte polarization coefficient of sterlet at different compositions of the pre-spawning feed

\begin{tabular}{ccccccc}
\hline \multirow{2}{*}{ Group } & \multirow{2}{*}{ Female № } & $\mathrm{I}_{1},{ }^{*} \mathrm{~cm}$ & \multirow{2}{*}{ Weight, $\mathrm{kg}$} & \multicolumn{2}{c}{ Egg size, $\mathrm{mm}$} & \multirow{2}{*}{ Oocyte polarization coefficient, \% } \\
\cline { 5 - 6 } Control & 1 & 61 & 2.09 & 2.42 & 2.23 & 9.65 \\
& 2 & 62 & 2.1 & 2.41 & 2.19 & 14.21 \\
& 3 & 63 & 2.1 & 2.44 & 2.18 & 13.42 \\
Experimennnnnnnn & 4 & 64 & 2.2 & 2.46 & 2.26 & 9.41 \\
& 1 & 65 & 2.4 & 2.43 & 2.21 & 8.08 \\
& 2 & 66 & 2.5 & 2.45 & 2.24 & 6.82 \\
& 3 & 66 & 2.4 & 2.46 & 2.20 & 7.03 \\
\hline
\end{tabular}

Note. Body length to the end of middle rays of the caudal fin. 
The histological picture of trophic inclusions in oocytes showed identity in their structure. Stable differences were registered in different intensities of incorporation of $\mathrm{P}^{32}$ into yolk phosphoproteins (Figure 3 $B, D)$. The majority of fish oocytes in the experimental group were characterized by destructive changes in their karyolemma indicating the end of the maturity stage IV (Figure 4).

Summarized data of cytomorphological parameters of sterlet oocytes are presented in Table 5 and they do not show any deviations in cellular parameters, as well as significant differences in the nuclear cytoplasmic ratio.

\section{Gonad Biopsy}

The use of a combined technology for the selection of females at stage IV (ultrasound scanning at the initial stage and subsequent application of the gonad biopsy method) allowed showing the peculiarities of oocyte nucleus polarization (Table 5).

Based on the data presented in Table 6, the average oocyte polarization coefficient in females of the control group, which had insignificantly varying lengths and weights (length 61-64 cm and weight 2.1-2.2 kg), was $13.81 \%$. The oocyte polarization coefficient in females of the experimental group with lengths of 65-66 $\mathrm{cm}$ and weights of $2.4-2.5 \mathrm{~kg}$ was $8.02 \%$.

\section{Discussion}

The justification for the use of butaphosphamide as an optimizing component in fish feeds consists in the experimentally proven significantly higher hemoglobin and serum protein concentrations in sterlet of the experimental group compared to the control that is an evidence of an increase in the homeostatic status of fish, which in conditions of a RAS corresponds to the optimal course of the pre-spawning period. Also, the use of Catosal in RAS conditions for sterlet rearing showed that butaphosphamide stimulated digestion in fish. A significant increase in the digestive tract fullnesses in fish of the experimental group compared to the control indicates the effectiveness of the proposed feeding scheme.

The results of this study showed that Catosal significantly improved liver function and stimulated biosynthesis of yolk phosphoproteins. Cyanocobalamin, which is included in Catosal and has a similar pharmacodynamics as ascorbic acid, is more preferable than the latter because its role in glycogenesis occurring in the liver is more important (Ponomarev et al., 2009; Khrustalev et al., 2017).

Glycogen is an energy reserve, which in case of glucose deficiency in the body can be quickly and optimally mobilized (Sveshnikova et al., 2019). The difference between the pathways of mobilization is directly related to the free energy required for oocyte maturation. The hydrolysis of glycogen to glucose results in a significant decrease in the level of free energy. An equivalent energy is required for the reverse process (the reaction of phosphorolysis of glycogen to glucose-1-phosphate). As histological analysis showed, the consumption of Catosal by fish allowed achieving balanced concentrations of glycogen and glucose-1phosphate in fish body, which at the micro level was expressed in a gradual attenuation of the lipostatic function of hepatocytes.

A shift in cellular function in the form of the activation of glycogen synthesis was expressed as a significant 1.2-fold decrease in the cell areas and a 1.3fold decrease in the nucleus areas. Fluctuations in the areas of cells and nuclei in a similar way are expected to result in a sharp shift of the nuclear cytoplasmic ratio. In reality, this did not happen. Stabilization of fluctuations of the nucleoplasmic ratio is a reflection of the adequacy of feeding and keeping conditions, while the opposite picture is observed under conditions of fatty degeneration of liver parenchyma associated with food or bacterial intoxication (Lenhardt et al., 2005; Kozij and Matvienko 2017; Chemagin, 2018).

Of interest is the fact that glucose-1-phosphate cannot penetrate beyond hepatocytes and remains in the cytoplasm until it loses phosphate. Most likely, the timely replenishment of phosphorus content in the liver of control fish occurred exclusively due to phosphoruscontaining components of the feed. However, in fish of the experimental group, the effect of phosphorus accumulation in the body was additionally enhanced by butaphosphamide, which was relatively actively involved in metabolic processes in the process of digestion. Thus, we believe that excess phosphorus in the form of butaphosphamide, which was present in fish body of the experimental group and for some reason

was not involved in the reaction of glycogen phosphorolysis, was transported to gonads, where it participated in the reactions of phosphoprotein biosynthesis. Direct evidence of this was the inclusion of $\mathrm{P}^{32}$-labeled butaphosphamide into the yolk granules.

According to available data (Podushka, 1999; Naumova et al., 2017), asynchrony in oocyte development periodically occurs in monoculture conditions, which can be explained by the influence of fish keeping conditions, individual characteristics of fish genetics, and the specificity of fish body reaction to feed composition.

Since the development of oocytes in critical periods of the transition from one stage to another is naturally accompanied by an increase in redox processes, the use of substances that are natural components of the tricarboxylic acid cycle (Krebs cycle) is very advisable, since the regulation of this process is of great importance for the successful finalization of oocyte maturation. Feeding fish with an optimized feed resulted in a shift towards initiation of vitellogenesis, which occurred soon after a short period of adaptation to feed components. Later, while the cytodynamics of oocytes and the associated change in the nucleoplasmic 

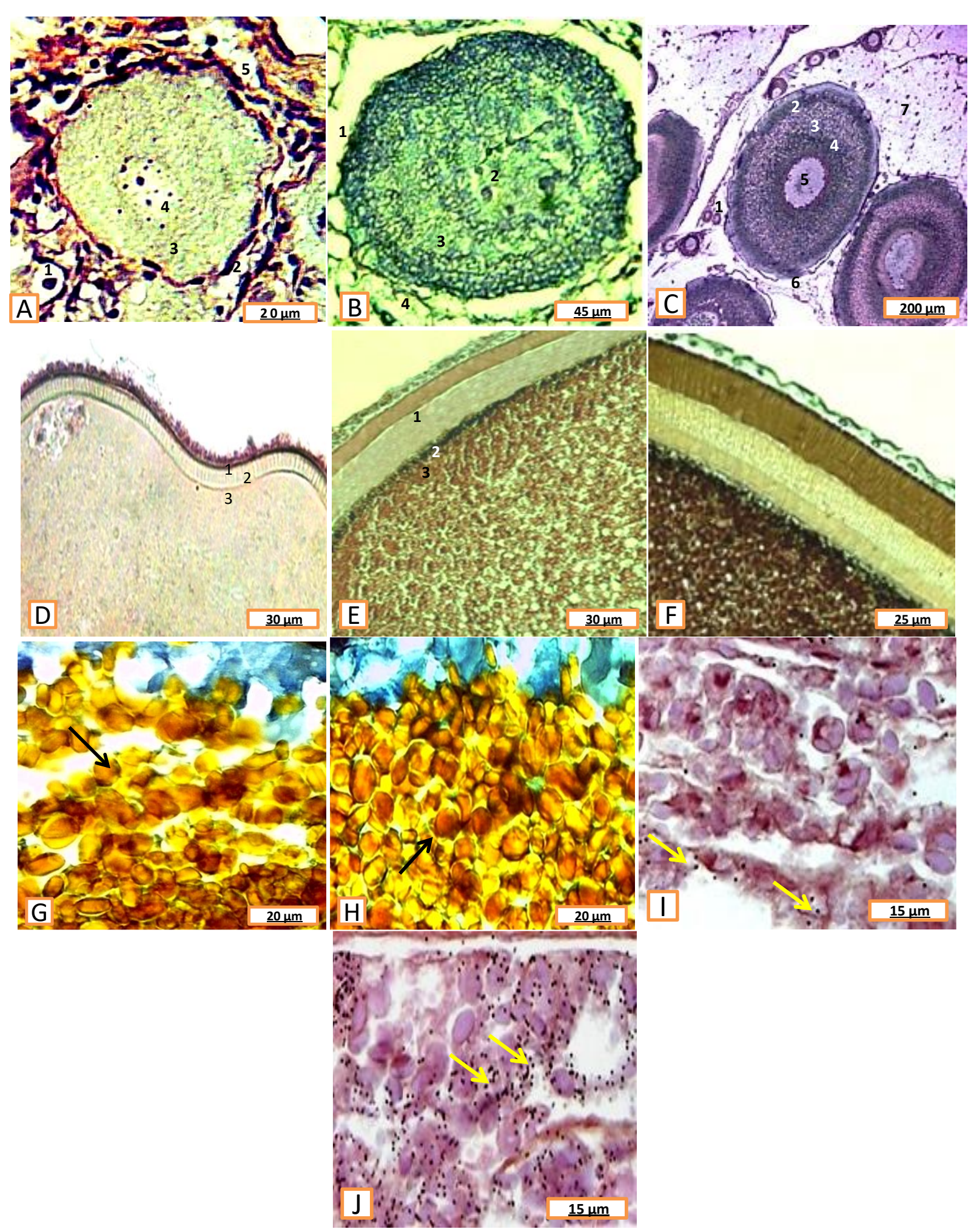

Figure 3. Sterlet oocytes on different stages of maturity.

A - control/experimental group (stage II):1 - oogonium of the "reserve fund"; 2 - oolemma; 3-ooplasm; 4-nucleus; 5 - connective tissue stroma. B - control/experimental group: 1 - oolemma; 2 - nucleus; 3 -ooplasm with lipid inclusions; 4 - connective tissue stroma. Böhmer's hematoxylin, Hart's fuchselin (modified). C - control group, stage II-III. 1 - oogonium of the "reserve fund"; 2 - peripheral yolk fraction; 3 - medium yolk fraction; 4 - perinuclear yolk fraction; 5 - nucleus; 6 - oolemma; 7 - connective tissue stroma. Böhmer's hematoxylin, Hart's fuchselin (modified). D experimental group, III stage (of formation of membrane components): 1 -zona radiata externa; 2 - zona radiata interna; 3 - peripheral yolk fraction. Böhmer's hematoxylin, Hart's fuchselin (modified). E - control group, IV stage (uncompleted): 1 - membrane; 2 - pigment inclusions; 3 peripheral yolk fraction. Böhmer's hematoxylin, Hart's fuchselin (modified). F - experimental group, maturity stage IV (completed): Böhmer's hematoxylin, Hart's fuchselin (modified). G - control group, $\mathrm{H}$ - experimental group maturity stage IV (uncompleted). Trophic inclusions of ooplasm. Native preparation. Picrofuxin. I - control group, J - experimental group maturity stage IV (uncompleted). Autoradiographs $\mathrm{P}^{32}$ in vitelline granules (shown by arrows). Native preparation. Heidenhain's iron hematoxylin. 


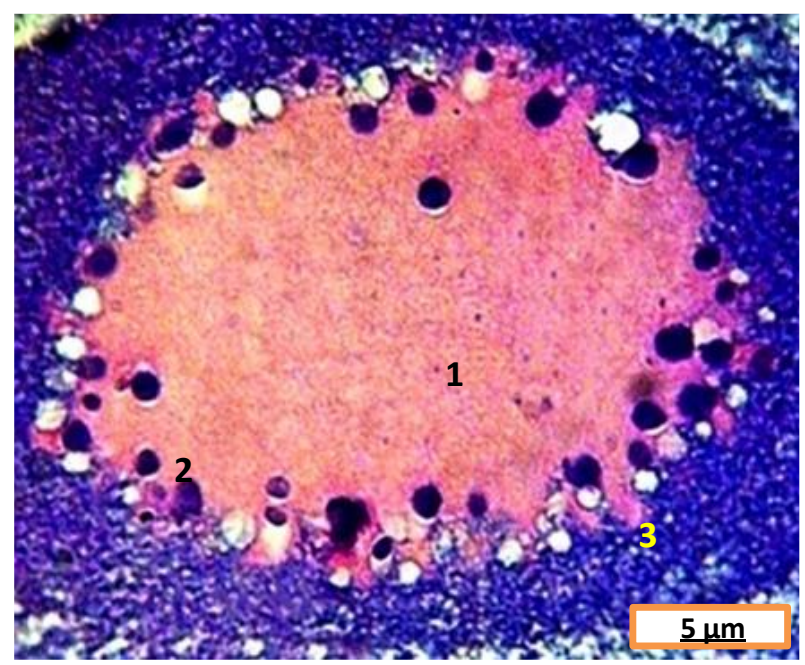

Figure 4. Collapsing nucleus of sterlet oocyte

Note: maturity stage IV (completed). 1 - ooplasm; 2 - nucleolus resorption; 3 - introduction of nucleoplasm into karyoplasm. Böhmer's hematoxylin, Hart's fuchselin (modified).

ratio within the studied groups were stable in the process of maturation, the polarization coefficient of the nucleus changed depending on feeding conditions.

\section{Conclusion}

The study demonstrated the sensitivity of fish body to feed composition, which was expressed as a positive change in the physiological status of organs and tissues. Studies of micro-adaptations of fish can help in assessing the effectiveness of feed mixtures in order to determine their optimal composition. The effect of Catosal on the sterlet body was shown as the reorientation of certain aspects of metabolism, which led to an accelerated growth, an increase in live weight, and an improvement in hematological parameters. The progressive dynamics of pre-spawning parameters was expressed in the acceleration of oocyte maturation and stimulation of vitellogenesis.

\section{Ethical Statement}

The study was carried out in accordance with the International Principles of the European Convention for the Protection of Vertebrate Animals used for Experimental and other Scientific Purposes (Strasbourg, 1986), the Declaration of Principles on Tolerance (28th session of UNESCO, Resolution 5.61, 1995), Law of Ukraine №3447 IV "On the Protection of Animals from III-Treatment ".

\section{Funding Information}

The study was funded by the Ministry of Education and Science of Ukraine (state registration 0118U005069) within the research: “Development and implementation of resource-saving technology for the production of fish products as a component of food security of Ukraine".

\section{Author Contribution}

Natalia Matvienko: Project Administration, Resources, Writing -original draft Conceptualization; Alexander Koziy: Formal Analysis, Investigation, Methodology, Funding Acquisition; Alexander Didenko: interpreted the results and wrote the manuscript with input from all authors; Issak Sherman: Visualization and Writing - review and editing.

\section{Conflict of Interest}

The authors declare that they have no known competing financial or non-financial, professional, or personal conflicts that could have appeared to influence the work reported in this paper.

\section{References}

Aldokhin, A.S., Volosnikov, G.I. (2018). A comparative analysis of morphometric indicators of sterlet in wintering holes of the lower Irthysh. Vestnik of Astrakhan State Technical University. Series: Fishing Industry, 4: 90-95.

Amineva, V.A., Yarzhombek, A.A. Physiology of fish. Moscow, Light and food industry, 1984. 200 p.

Bagrov, A.M., Bondarenko, L.G., Gamygin, E.A., Mamontov, Yu. P., Sergeant, L.A., Sklyarov, V.Y. (2014). Technologies for pond fish farming. Moscow, VNIRO, $360 \mathrm{p}$.

Buyarov, V.S., Yushkova, Yu.A (2016). Efficiency of using biologically active supplements in aquaculture. Bulletin of Orel State Agrarian University, 3(60): 30-39.

Chebanov, M.S., Galich, E.V. (2013). Sturgeon hatchery manual. FAO Fisheries and Aquaculture Technical Paper No. 558. Ankara, FAO, $297 \mathrm{pp}$.

Chemagin, A.A. (2018). Review of some aspects of sterlet (Acipenser ruthenus Linnaeus, 1758) ecology. Vestnik of Astrakhan State Technical University. Series: Fishing Industry, 2(66): 115-122.

Ivanov, A. (2000). Physiology of fish. St. Petersburg, Lan, 284 p. Kalaida, M.L., Govorkova L.K. (2013). Methods of fisheries research (study guide). St. Petersburg, Prospectus of 
Science, $288 \mathrm{p}$.

Khrustalev, E.I., Kurapova, T.M., Goncharenok, O.E., Molchanova, K.A. (2017). Feeds and feeding in aquaculture (textbook). St. Petersburg, Lan, $388 \mathrm{p}$.

Kozij, M. S.and Matvienko, N. N. (2017). Bioindication of Natural Waters Using a Histological Analysis of the Carassius Auratus Mesonephros Structure Journal of Water Chemistry and Technology, 39(3):177-180.

Koziy, M.S. (2002). Effect of biologically active substances on the histological structure of striated muscular tissue of «Concurrent» cross broiler embryos. Ukrainian Black Sea Region Agrarian Science, 5:177-180.

Koziy, M.S., Sherman, I.M., Samoyliuk, V.V. Matvienko N.N. 2016. General histology and embryology of fishes (textbook). Kherson: Grin D.S., 484 p.

Koziy, O.M., Sherman, I.M. (2018). Dynamics of microstructural changes of sterlet (Acipenser ruthenus) liver and gonads in the conditions of a closed recirculation system. Aquatic Bioresources and Aquaculture, 2:18-31.

Khmelnitsky, V., Mironov, S. (2010). Food for fish «Aller Aqua». Fish and seafood, 3 (51): 46-48.

Kurtiak, B.M., Simonov, R.P. (2000). Veterinary and sanitary expertise of food products in Ukraine: Regulatory documents (a guidebook), L: Leonorm, 1: $284 \mathrm{p}$.

Lenhardt, M., Prokes, M., Jaric, I., Barus, V., Kolarevic, J., Krupka, I., Cvijanovic, G., Cakic, P., Gacic, Z. (2005). Comparative analysis of morphometric characters of juvenile sterlet Acipenser ruthenus L. from natural population and aquaculture. Journal of Fish Biology,65: 320-320.

Medvedev, G.F., Gavrychenko, N.I., Begunov, V.S., Kukhtina, O.N. (2014). Therapeutic products, methods of the treatment and prevention of diseases of metrit complex and increase of caw reproductive ability. Issues of Legal Regulation in Veterinary Medicine, 3: 111-116.
Naumova, V.V., Kir'yaniv, D.A., Sveshnikova, E.V. (2017). Safety of sterlet grown in RAS conditions. Vestnik of Ulyanovsk State Agricultural Academy, 4 (40): 81-85 DOI 10.18286/1816-45-2017-4-81-85.

Ozeretskovskaya, N.G. (1964). To the question of the effect of a stable isotope of phosphorus and nitrogen on the absorption of radiophosphorus. Radioactive isotopes in hydrobiology and methods of sanitary hydrobiology. Moscow, Nauka, 76-83. [In Russian]

Podushka, S.B. (1999). Obtaining eggs from sturgeons with the preservation of life of brood fish. Scientific and Technical Bulletin of the Ichthyology Laboratory of the Center for International Environmental Cooperation, 2: 4-19.

Plemyashov, K.V., Moiseenko, D. O. (2010). Reproductive function of highly productive dairy cows with metabolic disorders and its correction. Issues of legal regulation in veterinary medicine., 1.: 37-40

Ponomarev, S.V., Ivanov, D.I. (2009). Sturgeon culture on an intensive basis (textbook). M: Kolos, $312 \mathrm{p}$.

Radionov, R.V. (2019). Use of a new pharmaceutical composition for treating dyspepsia in calves obtained from BLV-infected cows. Bulletin of KrasGAU, 2(143): $77-$ 84. [In Russian]

Seregin, I.G., Nikitchenko, V.E., Nikitchenko, D.A. (2018). Veterinary and sanitary requirements for slaughtering animals for meat in different countries of the world. Bulletin of Peoples' Friendship University of Russia. Series: Agronomy and Animal Husbandry, 13(1): 61-69.

Shakirov, O.F. (2009). Effect of $10 \%$ Catosal on metabolism and animals. Veterinary, 8: 11-12.

Smith, L.S. (1986). Introduction to the physiology of fish. Moscow, Agropromizdat, 1986. 168 p.

Sveshnikova, E.V., Naumova, V.V., Kir'yanov, D.A. (2019). A comparative characteristics of the use of metabolism energy of common and bighead carps. Vestnik of Ulyanovsk State Agricultural Academy, 3: 179-182. 